Case Report

\title{
Fondaparinux-associated Thrombocytopenia
}

\author{
Jahanzeb Malik', Nismat Javed ${ }^{2}$, Matiullah Kamin
}

\begin{abstract}
Heparin-induced thrombocytopenia (HIT) is an immune-mediated condition causing thrombocytopenia and paradoxical thrombosis after exposure to heparin or low-molecular-weight heparin. It has been rarely reported by Fondaparinux, an artificial pentasaccharide similar to heparin. This manuscript presents a case of HIT associated with fondaparinux use.
\end{abstract}

KEYWORDS: Factor Xa inhibitor, Fondaparinux-associated thrombocytopenia, HIT.

doi: https://doi.org/10.12669/pjms.37.2.3522

How to cite this:

Malik J, Javed N, Kamin M. Fondaparinux-associated Thrombocytopenia. Pak J Med Sci. 2021;37(2):598-599.

doi: https://doi.org/10.12669/pjms.37.2.3522

This is an Open Access article distributed under the terms of the Creative Commons Attribution License (http://creativecommons.org/licenses/by/3.0), which permits unrestricted use, distribution, and reproduction in any medium, provided the original work is properly cited.

\section{INTRODUCTION}

Heparin-induced thrombocytopenia (HIT) is a prothrombotic condition associated with heparin exposure. ${ }^{1}$ The immunoglobulin G antibodies, which clump heparin molecule and platelet factor 4 , causes the clinical syndrome of thrombocytopenia and thrombo-occlusive manifestations. ${ }^{2}$ HIT typically occurs after 5 to 10 days of exposure to heparin. ${ }^{2}$ This syndrome is most commonly associated with unfractionated heparin while it is described uncommonly with low-molecular-weight heparin., ${ }^{3,4}$ Fondaparinux is a synthetic pentasaccharide that inhibits

1. Dr. Jahanzeb Malik,

Rawalpindi Institute of Cardiology,

Rawalpindi, Pakistan.

2. Dr. Nismat Javed,

Shifa College of Medicine,

Shifa Tameer-e-Millat University,

Islamabad, Pakistan.

3. Dr. Matiullah Kamin,

Shifa International Hospital,

Islamabad, Pakistan.

Correspondences:

Dr. Jahanzeb Malik, Rawalpindi Institute of Cardiology, Rawalpindi, Pakistan.

Email: Heartdoc86@gmail.com

* Received for Publication:

August 20, 2020

* Revision Received:

* Revision Accepted: factor Xa by binding to antithrombin III. ${ }^{4}$ In lowrisk Non-ST elevation myocardial infarction (NSTEMI), it is as effective as unfractionated heparin or low-molecular-weight heparin. ${ }^{5}$ Due to the mechanism of action, Fondaparinux is not able to bind the platelet Factor- 4 to generate immune complexes leading to platelet activation. The risk of HIT is thought to be negligible with Fondaparinux, proposing this as a safe drug in the treatment of HIT itself, along with other indications. ${ }^{6}$ We describe a case of HIT associated with fondaparinux in a patient with acute coronary syndrome.

Patient and observation: A 46 years-old male presented with complaints of central on-going chest pain which started a week ago. Taking it as acid peptic disease he did not consult any medical personnel until it worsened since yesterday. He was diagnosed as NSTEMI based on ECG and Troponin-I essay. His comorbid included a family history of ischemic heart disease and smoking. His thrombolysis in myocardial infarction (TIMI) score was two and the Global Registry of Acute Coronary Events (GRACE) score was 102. Guideline directed medical therapy (GDMT) was started. He was given Fondaparinux 2.5 mg once daily till hospitalization. At baseline, his platelets were $256,000 / \mu \mathrm{L}$. On the second day, platelets dropped to $110,000 / \mu \mathrm{L}$. They 
were repeated on the suspicion of lab error, which showed $90,000 / \mu \mathrm{L}$. His history was not significant for dengue or associated infections and thrombocytopenia. His platelet Factor-4 was positive. Autoimmune profile and viral serology were normal. After ruling out the common causes of thrombocytopenia, the diagnosis of HIT was made. Fondaparinux was discontinued and intravenous infusion of lepirudin was started. The next day platelet count increased to 148,000 / $\mu \mathrm{L}$. The following day, the count was $205,000 /$ $\mu \mathrm{L}$. After three days of lepirudin intravenous infusion, it was discontinued and the patient was discharged on clopidogrel $75 \mathrm{mg}$ with a platelet count of $223,000 / \mu \mathrm{L}$. On follow-up after two weeks his platelets were $220,000 / \mu \mathrm{L}$.

\section{DISCUSSION}

Thrombocytopenia associated with heparin is a common complication seen in every day clinical practice. Treatment of HIT constitutes discontinuing heparin and substituting direct thrombin inhibitors (DTIs). ${ }^{7}$ Lepirudin and Argatroban are the commonly used DTIs in HIT. Newer DTI include bivalirudin. Fondaparinux, another DTI, has also been used in HIT with successful results. ${ }^{7}$ In our case, however, fondaparinux was involved in causing HIT after the first dose. The platelets decreased by approximately 50\%. After discontinuing Fondaparinux platelet count increased to normal value. This indicates a role of Fondaparinux in causing HIT in sporadic cases. On literature review, eight cases of thrombocytopenia with this factor Xa inhibitor since 2007 have been reported. ${ }^{8-10}$

\section{CONCLUSION}

Despite many reports of successful treatment of HIT with fondaparinux, there seems to be a possibility of fondaparinux causing HIT, as suggested by our case report. Further trials are necessary to clarify the mechanism behind fondaparinux-associated thrombocytopenia.

\section{Learning Points:}

- Heparin-induced thrombocytopenia is fairly common but Fondaparinux causing decreased platelets is not seen regularly.

- In the literature, Fondaparinux has been used successfully for the treatment of heparininduced thrombocytopenia in addition to conventional direct thrombin inhibitors.
- Our case shows one of the nine reports in the literature since the first presentation of Fondaparinux-associated thrombocytopenia in 2007.

Conflict of interests: None.

\section{REFERENCES}

1. Patriarcheas V, Pikoulas A, Kostis M, Charpidou A, Dimakakos E. Heparininduced Thrombocytopenia: Pathophysiology, Diagnosis and Management. Cureus. 2020;12(3):e7385. doi: 10.7759/cureus.7385

2. Tardy B, Lecompte T, Mullier F, Vayne C, Pouplard C. Detection of Platelet-Activating Antibodies Associated with Heparin-Induced Thrombocytopenia. J Clin Med. 2020;9(4):1226. doi: 10.3390/jcm9041226

3. Gruel Y, De Maistre E, Pouplard C, Mullier F, Susen S, Roullet $S$, et al. Diagnosis and management of heparininduced thrombocytopenia. Anaesth Crit Care Pain Med. 2020;39(2):291-310.

4. Kounis NG, Koniari I, Soufras GD, Tsigkas G, Plotas $\mathrm{P}$, Davlouros $\mathrm{P}$, et al. The paradox of heparin induced thrombocytopenia-thrombosis, the role of fondaparinux and the need for new therapeutic strategies. Int Angiol. 2020;39(4):350-351. doi: 10.23736/S0392-9590.20.04364-3

5. Khodabandeh S, Biancari F, Kinnunen EM, Mariscalco G, Airaksinen J, Gherli R, et al. Perioperative Bleeding in Patients With Acute Coronary Syndrome Treated With Fondaparinux Versus Low-Molecular-Weight Heparin Before Coronary Artery Bypass Grafting. Am J Cardiol. 2019;123(4):565-570. doi: 10.1016/j.amjcard.2018.11.028

6. Schindewolf M, Steindl J, Beyer-Westendorf J, Schellong S, Dohmen PM, Brachmann J, et al. Frequent off-label use of fondaparinux in patients with suspected acute heparin-induced thrombocytopenia (HIT)- findings from the GerHIT multi-centre registry study. Thromb Res. 2014;134(1):29-35. doi: 10.1016/j.thromres.2014.03.029

7. Al-Rossaies A, Alkharfy KM, Al-Ayoubi F, Al-Momen A. Heparin-induced thrombocytopenia: Comparison between response to fondaparinux and lepirudin. Int J Clin Pharm. 2011;33(6):997-1001.

8. Re G, Legnani C. Thrombocytopenia during fondaparinux prophylaxis: HIT or something different? Intern Emerg Med. 2010;5(4):361-363.

9. Warkentin TE, Sheppard JA, Manheim JC. HIT complicating fondaparinux prophylaxis: Fondaparinux-dependent platelet activation as a marker for fondaparinux-induced HIT. Thromb Haemost. 2014;112(6):1319-1322.

10. Alsaleh KA, Al-Nasser SM, Bates SM, Patel A, Warkentin TE, Arnold DM. Delayed-onset HIT caused by low-molecularweight heparin manifesting during fondaparinux prophylaxis. Am J Hematol. 2008;83(11):876-878.

\section{Author's Contributions:}

JM: Idea, design, and editing of final draft. He takes the responsibility and is accountable for all aspects of the work in ensuring that questions related to the accuracy or integrity of any part of the work are appropriately investigated and resolved.

NJ: Case selection and manuscript writing.

MK: Manuscript writing and supervision. 